\title{
INOVAÇÕES PEDAGÓGICAS NO SETOR LITORAL DA UNIVERSIDADE FEDERAL DO PARANÁ (UFPR) E SEUS DESDOBRAMENTOS NA LICENCIATURA EM LINGUAGEM E COMUNICAÇÃO
}

\section{PEDAGOGICAL INNOVATIONS AT UFPR'S SETOR LITORAL AND THEIR EFFECTS ON LANGUAGE AND COMMUNICATION TEACHER EDUCATION}

\section{David José de Andrade Silva*}

RESUMO: O ensino superior tem sido desafiado a realizar mudanças em sua estrutura pedagógica, seja por uma reivindicação da comunidade universitária ou pela legislação. O Setor Litoral da Universidade Federal do Paraná (UFPR) propõe inovações pedagógicas nos cursos que oferta, dentre eles a licenciatura em Linguagem e Comunicação. O presente trabalho visa discutir os pressupostos que nortearam os conceitos de inovação curricular no ensino superior e como a graduação em destaque lida com os elementos inovadores.

PALAVRAS-CHAVE: Ensino superior. Inovação curricular. Licenciatura.

ABSTRACT: The higher education is being challenged to change its pedagogical structure, demanded by the university community or by the law. UFPR's Setor Litoral proposes pedagogical innovations in its undergraduate programs, among them the Language and Communication teacher education. The present paper aims to debate the backgrounds that led the concepts of curriculum innovation in

Professor da Universidade Federal do Paraná/ Setor Litoral (Matinhos). Mestre em Letras pela UFPR. E-mail: dajoas@gmail.com 
higher education and how the highlighted undergraduate degree deals with the innovative elements.

KEYWORDS: Higher education. Curriculum innovation. Language. 


\section{INOVAÇÕES PEDAGÓGICAS NO SETOR LITORAL DA UNIVERSIDADE FEDERAL DO PARANÁ (UFPR) E SEUS DESDOBRAMENTOS NA LICENCIATURA EM LINGUAGEM E C}

\section{INTRODUÇÃO}

Ocorreram vários investimentos no âmbito educacional brasileiro no período de 2003 a 2010, dentre eles a expansão universitária, que deu origem a novas universidades ou campi interiorizados. A primeira fase é conhecida como "Programa Expansão" (BRASIL, s/d: V) e durou até 2007, quando o Ministério da Educação (MEC) lançou o plano de Reestruturação e Expansão Universitária (REUNI), cuja proposta encontra-se ainda em vigência na atual gestão presidencial.

O objetivo desta política pública era propiciar o acesso ao ensino federal por meio da ampliação das vagas e da permanência dos estudantes na universidade (auxílios e benefícios aos estudantes), principalmente em regiões de fragilidade social e econômica. Além disso, as novas unidades teriam o desafio de planejar pedagogicamente a oferta de cursos que contemplassem as necessidades sociais da região onde fossem implantados e acompanhar a modernização teórico-metodológica iniciada após a atual Lei de Diretrizes e Bases da Educação Nacional n $9.394 / 96$ (doravante LDB), com as resoluções e pareceres do Conselho Nacional de Educação. 
Nesse contexto, o estado do Paraná foi contemplado com a criação de novas instituições federais de ensino superior (IFES) e ensino básico, técnico e tecnológico (IF) nas duas fases: o Centro Federal de Ensino Técnico (CEFET-PR) tornou-se a Universidade Tecnológica Federal do Paraná (UTFPR) em 2005, inaugurando novos campi em Apucarana, Francisco Beltrão, Guarapuava, Londrina e Toledo; a Escola Técnica da Universidade Federal do Paraná (ETUFPR) desmembrou-se da universidade em 2008 e tornou-se o Instituto Federal do Paraná (IFPR), que possui atualmente 14 campi espalhados pelo estado (Assis Chateaubriand, Campo Largo, Cascavel, Curitiba, Foz do Iguaçu, Irati, Ivaiporã, Jacarezinho, Londrina, Palmas, Paranaguá, Paranavaí, Telêmaco Borba e Umuarama); a Universidade Federal da Integração Latino-Americana (UNILA) em Foz do Iguaçu; os campi de Realeza e Laranjeiras do Sul da Universidade Federal da Fronteira Sul (UFFS), cuja sede administrativa (reitoria) pertence a Chapecó/SC; e o Setor Litoral da Universidade Federal do Paraná (UFPR), localizado em Matinhos, objeto deste trabalho.

O Setor Litoral é resultado de um esforço conjunto entre as três esferas governamentais (federal, estadual e municipal) com o intuito de promover o desenvolvimento sustentável dos sete municípios do litoral paranaense (Antonina, Guaraqueçaba, Guaratuba, Matinhos, Morretes, Paranaguá e Pontal do Paraná) com extensão ao Vale do Ribeira. Operante desde 2005, atualmente possui 15 cursos de graduação (oito bacharelados, três licenciaturas e quatro tecnólogos), quatro especializações (três na modalidade EaD e uma presencial) e um curso de aperfeiçoamento. A principal característica do campus é seu Projeto Político-Pedagógico (PPP), cujos pressupostos organizam as ações de ensino, pesquisa, extensão e gestão nos princípios da educação emancipatória e dialogam fortemente com as inovações pedagógicas previstas nas diretrizes do MEC.

Outra peculiaridade que chama a atenção no campus é a nomenclatura dos cursos: apenas dois (Fisioterapia e Serviço Social) possuem diretrizes curriculares. Assim, os cursos de bacharelado em Gestão Ambiental, Gestão Desportiva e de Lazer, Gestão e Empreendedorismo, Gestão Pública, Informática e Cidadania, Saúde Coletiva, os tecnólogos em Agroecologia, Gestão de Turismo, Gestão Imobiliária e as licenciaturas em Artes, Ciências 
e Linguagem e Comunicação teriam, cada um em sua natureza e especificidade, referência nas graduações regulamentadas, mas com flexibilidade curricular maior.

O presente trabalho focará nas atividades de ensino do curso de Licenciatura em Linguagem em Comunicação (doravante LinCom), criado em 2009 no Setor Litoral, partindo da relação entre o PPP e o Projeto Pedagógico do Curso (PPC) e seus desdobramentos. Procurar-se-á discutir como se desenvolve a trajetória acadêmica dos discentes ao longo dos quatro anos (mínimos) de formação e compartilhar inquietações no que tange às inovações curriculares e suas necessidades estruturais para se efetivarem.

\section{CONTEXTO MACRO: A ORIGEM DO(S) PROJETO(S) LITORAL}

O Setor Litoral foi criado, conforme exposto anteriormente, a partir de uma política pública de expansão universitária do governo federal que, por alinhamento político-ideológico, obteve apoio da Administração Superior da UFPR, do governo estadual e municipal à época de sua criação. De acordo com o PPP (UNIVERSIDADE FEDERAL DO PARANÁ, 2008: 1):

A UFPR Litoral, hoje Setor Litoral e seu Projeto Político-Pedagógico, teve sua gênese na plataforma para eleição da reitoria da Universidade no ano de 2001, para gestão de 2002-2006. A proposta foi fundada com a intencionalidade de representar mais do que a ampliação de vagas no ensino superior, fato este que por si só já seria significante, mas instalou um Projeto inovador em uma região geográfica desacreditada historicamente e com uma grande debilidade econômica. (grifo meu)

Outro componente, de relevância para a criação do campus, não citado no documento, mas de conhecimento público da equipe de trabalho, seria a construção de um espaço dotado de uma nova concepção de ensino superior (ES) que poderia inspirar renovação para uma universidade aproximando- 
-se do centenário (completado em 2012) e de práticas pedagógico-administrativas consolidadas. Assim, destaco mais três aspectos nesse percurso: o PPP é concebido localmente por um núcleo estratégico da universidade e assumido como um compromisso político-eleitoral; o empreendimento é viabilizado por uma iniciativa de proporção nacional; o apoio estadual e municipal cria condições para sustentação articulada, mas fragiliza a exequibilidade à medida que ocorrem alternâncias de poder (que, apesar de serem naturais, são mais difíceis de gerir pela proximidade e uma possível contestação quanto à aplicação de recursos em algo de responsabilidade de outra esfera governamental). E onde se enquadram os reais atores para consolidação do "Projeto inovador", ou seja, corpo discente, docente e técnico? Masetto (2012: 233) prevê que:

Não há possibilidade de qualquer inovação acontecer e se implantar quando imposta de cima para baixo ou de fora para dentro por melhor que seja o projeto. $\mathrm{O}$ sentimento de "pertença" ao projeto é fundamental ser vivenciado e trabalhado desde o início. A maior presença e coesão desse grupo pode determinar o ritmo de implantação da inovação.

Fiz essas observações para mostrar que foram necessárias várias amarrações para conceber o campus e que o "código genético" do PPP possui, em seu "DNA", elementos políticos (partidários e ideológicos) de um coletivo diferente do esperado para sua construção. Veiga (2003: 277) destaca que, dentre as características fundamentais do PPP, "A legitimidade de um projeto político-pedagógico está estreitamente ligada ao grau e ao tipo de participação de todos os envolvidos com o processo educativo, o que requer continuidade de ações.”. Pode-se estar construindo uma falácia em prol de um "democratismo" ou "participacionismo", no qual tudo deve ser decidido coletivamente e em igualdade de condições, mas quando os pressupostos basilares (os quais serão apresentados a seguir) são pré-concebidos, pouco resta aos efetivos protagonistas decidir, além de assumir a tarefa de executar o que foi pensado por um grupo desvinculado do desenvolvimento do projeto. 
A constituição estrutural do Setor Litoral é composta pelas seguintes contrapartidas governamentais: o governo federal é responsável pelos insumos (tecnológicos, pessoal, equipamentos); o estadual cedeu e reformou um edifício para a sede, além de construir mais dois prédios (laboratórios e salas de aula), a biblioteca e o auditório; o municipal se encarregaria dos serviços gerais, segurança e despesas com água e eletricidade. O primeiro termo de cooperação foi assinado em 2005, com validade de 5 anos, e o segundo em 2010. Na primeira assinatura, apenas a prefeitura municipal de Matinhos era cossignatária, mas na segunda os demais municípios da região litorânea aderiram ao documento. Assim, um campus universitário que poderia "apenas" cumprir as metas estipuladas pelo MEC e da comunidade interna e externa, passa a ter de se comprometer com as expectativas de 10 instâncias político-administrativas (os municípios, o estado, a União e a reitoria). Logo, paradoxalmente (ou não?), um projeto que se discursa emancipatório e inovador é norteado mais por forças extrínsecas do que intrínsecas, também considerando a natureza das autarquias públicas, excessivamente regulatórias e burocráticas. Mas são outros aspectos que mais me chamam a atenção. Vejamos.

A fundamentação epistemológica do PPP embasa-se na perspectiva da educação emancipatória e nas tendências pós-modernistas. A universidade aproxima-se da sociedade para dialogar, estreitar relações e tecer novos saberes no intuito de sair da relação de uso para fortalecer um compromisso mútuo. Explorarei mais adiante as questões pedagógicas e, por enquanto, continuarei com o pano de fundo do projeto. Assim, segundo o PPP (UNIVERSIDADE FEDERAL DO PARANÁ, 2008: 6):

A proposição do Projeto Político-Pedagógico do Setor Litoral da UFPR quer superar os pressupostos da modernidade e lançar-se na construção de um projeto inovador e emancipatório. Para tal, toma como princípio a reflexão acerca da realidade concreta do lugar, como fonte primeira, para, em diálogo com o conhecimento sistematizado, tecer a organização curricular e o desenvolvimento de projetos que devem partir dos alunos e envolver os professores e a comunidade. 
A criação dos cursos de graduação pautou-se, para dar conta das intencionalidades do PPP, em: articular ações com a Educação Básica (EB) pública; permitir uma flexibilidade curricular que permitisse aos discentes possibilidades para além da formação técnica e mais autônoma; estimular o ingresso da classe trabalhadora ao ensino superior abrindo cursos preferencialmente no período noturno (atualmente, 11 dos 15 cursos são noturnos); atender as demandas e características históricas, sociais e econômicas da região; primar por corpo docente interdisciplinar nos colegiados (doravante câmaras de curso), com aproximadamente 7 professores específicos (variando para pouco mais ou para menos); utilizar estratégias teórico-metodológicas diferenciadas de ensino-aprendizagem, buscando superar a lógica disciplinar; e utilizar instrumentos e critérios de avaliação que valorizem o processo e a construção coletivo-cooperativa do conhecimento, ofertando possibilidades de acompanhamento pedagógico nos casos em que o/a discente não consegue atingir os objetivos propostos. E como sustentar legalmente essas escolhas?

No âmbito pedagógico, o Parecer CNE/CES n776/97 de 3 de dezembro de 1997 instituiu a Orientação para as diretrizes curriculares dos cursos de graduação, cujo objetivo seria subsidiar as discussões em âmbito universitário para as Diretrizes Curriculares Nacionais (DCN) das licenciaturas e bacharelados. O contexto de surgimento desse parecer é influenciado pela recém aprovação da LDB vigente, pela nova configuração do Conselho Nacional de Educação (CNE) e pelos anseios da comunidade acadêmica para se efetivarem as melhorias na educação pós-regime militar. Entretanto, uma das principais críticas dos especialistas em educação era que havia uma visível influência neoliberal (característica do governo Fernando Henrique Cardoso) na concepção educacional do ES. Segundo Santos (2005: 23-24), a ascensão da indústria de alta tecnologia na Europa e EUA nos anos de 1970 impactou na necessidade de formação de mão-de-obra qualificada que influenciou, a partir da década de 1990, a construção de currículos que atendessem à demanda do mercado. Assim, a intencionalidade de flexibilizar, transversalizar e encurtar o processo de ensino universitário tem, em seu bojo, o atendimento dos interesses das elites empresariais. A presença dessas questões pode ser percebida nos aspectos que constam no parecer (BRASIL, 1997: 2): 
1. Assegurar, às instituições de ensino superior, ampla liberdade na composição da carga horária a ser cumprida para a integralização dos currículos, assim como na especificação das unidades de estudos a serem ministradas;

2. Indicar os tópicos ou campos de estudo e demais experiências de ensino-aprendizagem que comporão os currículos, evitando ao máximo a fixação de conteúdos específicos com cargas horárias pré-determinadas, as quais não poderão exceder $50 \%$ da carga horária total dos cursos;

3. Evitar o prolongamento desnecessário da duração dos cursos de graduação;

4. Incentivar uma sólida formação geral, necessária para que o futuro graduado possa vir a superar os desafios de renovadas condições de exercício profissional e de produção do conhecimento, permitindo variados tipos de formação e habilitações diferenciadas em um mesmo programa;

5. Estimular práticas de estudos independente, visando uma progressiva autonomia profissional e intelectual do aluno;

6. Encorajar o reconhecimento de habilidades, competências e conhecimentos adquiridos fora do ambiente escolar, inclusive os que se refiram à experiência profissional julgada relevante para a área de formação considerada;

7. Fortalecer a articulação da teoria com a prática, valorizando a pesquisa individual e coletiva, assim como os estágios e a participação em atividades de extensão.

8. Incluir orientações para a condução de avaliações periódicas que utilizem instrumentos variados e sirvam para informar a docentes e a discentes acerca do desenvolvimento das atividades didáticas.

Se, por um lado, vários dos aspectos acima são desejados por aqueles que realmente querem realizar transformações positivas no ES, como propiciar que os estudantes tenham menos amarras curriculares e pedagógicas para protagonizar sua trajetória acadêmica, por outro lado, não se pode ignorar uma prática de "fazer o mínimo que a legislação manda" ou "fazer para inglês ver". Ou seja, seguir as diretrizes e implementar mudanças nos cursos não significa necessariamente uma melhoria qualitativa, pois depende de como a IES se organiza. Gatti (2009: 77), em sua pesquisa sobre o estado da arte 
das licenciaturas (foco deste trabalho) em Letras/ Português ${ }^{1}$, considera que a adesão plena dos cursos às diretrizes pode revelar várias incoerências o que, em suas palavras, "nos faz levantar a suspeita de que as diretrizes podem estar mais presentes no plano da retórica do que no da ação pedagógica.” Ilustro a preocupação de Gatti a partir da matriz mínima de uma licenciatura, ressaltando que a formação de professores para a EB é rigorosamente legislada, inclusive na distribuição de carga horária. Até 2007, das 2.800 horas mínimas para qualquer curso de habilitação única, 400 são destinadas aos estágios supervisionados, 400, à prática como componente curricular, 200, a outras formas de atividades acadêmico-científico-culturais e 1.800, aos conteúdos curriculares de natureza científico-cultural ${ }^{2}$. Em normativas complementares, somente o curso de Pedagogia (com habilitação em séries iniciais) manteve essa organização de carga horária, tendo os demais cursos obtido a possibilidade de retirar 100 horas de estágio supervisionado e integrar nas outras atividades formativas pelo Parecer CNE/CP n09/2007 de 5 de dezembro de 2007. Além dessa alteração, outras legislações também determinaram a inclusão de temas específicos, como: História e Cultura Afro-Brasileira (Lei 10.639, de 9 de janeiro de 2003), nas áreas de Educação Artística, Literatura e História Brasileira; Cultura e História Indígena (Lei 11.645, de 10 de março de 2008), nas mesmas áreas abrangidas pela cultura afro-brasileira; e Língua Brasileira de Sinais - LIBRAS (Decreto n5.626, de 22 de dezembro de 2005), cuja inclusão como disciplina iniciou-se (com prazo de três anos para inserção) nos cursos de Educação Especial, Fonoaudiologia, Pedagogia e Letras. Podemos constatar que os cursos de formação de professores de língua e literatura (caso da licenciatura em LinCom) são os mais afetados e há muita pauta a ser tratada em apenas três anos e meio (considerando os cursos de 2.800 horas). A consequência disso é uma situação difícil de equacionar para os colegiados: estender a formação, correndo o risco de ver diminuir mais a procura, pois, em média, os maiores empregadores de professores são os municípios e estados e estes pagam baixos salários; manter o tempo reduzido e correr o risco de ter um curso

1 Também são analisados no trabalho, Pedagogia, Ciências Biológicas e Matemática.

2 Parece pouca carga horária, mas antes era menor ainda, variando de cursos de 2.200 a 2.900 horas (SAVIANI, 2009: 147). 
polivalente e superficial. A seguir, trataremos de outros processos decisórios com variáveis relevantes.

No âmbito administrativo, apesar de o Setor Litoral ter sido criado na primeira fase de expansão universitária, há várias interfaces com três das cinco dimensões de abrangência do programa REUNI (BRASIL, 2007: 11), quais sejam: aumento de vagas de ingresso, especialmente no período noturno; revisão da estrutura acadêmica buscando a constante elevação da qualidade; reorganização dos cursos de graduação; diversificação das modalidades de graduação, preferencialmente com superação da profissionalização precoce e especializada; implantação de regimes curriculares e sistema de títulos que possibilitem a construção de itinerários formativos; articulação da educação superior com a educação básica, profissional e tecnológica; atualização de metodologias (e tecnologias) de ensino-aprendizagem. O valor total do aporte de recursos proposto para ser distribuído entre as universidades que aderiram ao programa era de aproximadamente dois bilhões de reais. Porém, embora o orçamento e as intencionalidades fossem sedutoras, o fato que causou controvérsia e acalorou os debates nos conselhos universitários foram as duas metas globais (BRASIL, 2007: 12): taxa de conclusão média de noventa por cento nos cursos de graduação presenciais; e relação de dezoito alunos de graduação por professor em cursos presenciais. A primeira é um desafio institucional de grandes proporções, tendo em vista a evasão (BRASIL, 2007: 8) diagnosticada nas universidades. A segunda poderia esclarecer o quantitativo de docentes por curso no Setor Litoral: por exemplo, o curso de LinCom tem 140 vagas (contabilizando 35 para cada um dos quatro anos de formação mínima recomendada), que resultaria, arredondando para cima, num total de oito docentes.

Ao prever uma formação generalista, de menor duração e voltada para o mercado, uma das linhas de análise dessas premissas associou o movimento como uma resposta às demandas econômicas das empresas privadas, tal como abordamos anteriormente a partir de Santos (2005). Catani, Oliveira e Dourado (2001: 77) abordam o assunto nos seguintes termos:

A questão central nesse cenário de diversificação e diferenciação da educação superior no Brasil, no tocan- 
te à reformulação curricular dos cursos de graduação, não parece ser o da flexibilização curricular em si, uma vez que esta é expressão de diferentes concepções e desdobramentos acadêmicos. Por essa razão, é preciso ter claro que a política oficial, ao se apropriar e redirecionar essa temática, em uma perspectiva pragmática e utilitarista de ajuste ao mercado, reduz a função social da educação superior ao ideário da preparação para o trabalho, a partir da redefinição de perfis profissionais baseados em habilidades e competências hipoteticamente requeridas pelo mercado de trabalho em mutação.

Apesar de as críticas de Santos (2005) e Catani, Oliveira e Dourado (2001) serem direcionadas ao contexto do governo FHC, que buscava a reforma do ensino superior pela privatização, a lógica da formação para a preparação técnica/tecnológica vinculada ao mercado de trabalho e desenvolvimento econômico está latente nos governos Lula e Dilma. A criação dos Institutos Federais é uma prova concreta disso e atualmente absorve recursos vultosos para criar a maior rede de educação federal do país sob a tutela do MEC, tendo em vista que os IFs não possuem a prerrogativa da autonomia universitária. A gestão universitária também é afetada pelo ideário neoliberal, em termos de eficiência e eficácia administrativa, que implicará instrumentos de otimização de recursos, como a condução de uma graduação de quatro anos tendo, em média, dois professores por turma.

$\mathrm{Na}$ sequência, apresentam-se algumas discussões sobre inovação curricular no ensino superior e quais são suas principais características.

\section{INOVAÇÃO CURRICULAR: O VELHO-NOVO, O NOVO-VELHO E O NOVO-NOVO}

Inovar significa, segundo o minidicionário Aurélio (FERREIRA, 2009: 480), "renovar, introduzir novidade em". Ainda na mesma fonte, no verbete renovar (idem, ibidem: 697) encontramos as seguintes acepções: "tornar 
novo ou como novo; modificar, introduzindo novos elementos; substituir por algo novo do mesmo tipo". Essas definições podem propiciar algumas abstrações. Primeiro, há algo velho/ de longa data em vigência que pode estar ultrapassado/obsoleto. Segundo, o novo pode ser um substituto do velho, mantendo exatamente suas características (como a troca de uma fralda velha por uma nova). Terceiro, o novo pode ser uma versão atualizada do velho, mantendo sua essência nos aspectos estruturais (como os programas de edição de textos, que incorporam novas funcionalidades e recursos, mas mantêm a principal funcionalidade). E, por fim, o novo pode ser algo totalmente inédito, sem referências diretas para comparação, cuja aceitação e adaptação pela sociedade se faz gradualmente (o advento da telefonia móvel há quase vinte anos criou uma nova cultura na geração de tecnologia, no mundo da comunicação e nas relações interpessoais). E como trazer esses pressupostos para o mundo educacional?

Santos (2010) discute sobre a crise do conhecimento científico moderno, que ele chama de paradigma dominante, cujo método de observação e análise da realidade sustenta-se na divisão em parcelas mínimas, na rigidez e na neutralidade (esta significa o distanciamento do observador do objeto a fim de eliminar valores subjetivos ao processo). A contraposição a esse tipo de produção de saber o pesquisador chama de paradigma emergente, que traz novamente a ideia de conhecimento compartilhado, integrado, interdependente e, principalmente, socialmente comprometido. O espaço escolar, independentemente do nível, testemunha, influencia e é influenciado pelas transformações sociais, econômicas e políticas ao longo dos séculos e, portanto, a crise preconizada por Santos já é sentida nas salas de aula. Os tensionamentos entre as instituições, com anos de práticas pedagógicas acumuladas, e seus atores, nascidos ou criados na era da tecnologia e da informação, provocaram a necessidade, dentre muitas outras, de repensar a construção de projetos pedagógicos que abarcassem as demandas do século vigente. Assim, era preciso, então, inovar. Mas em qual/que sentido/direção? Cunha (2003: 150) postula que:

As inovações que adivinhamos próximas se materializam pelo reconhecimento de formas alternativas de sa- 
beres e experiências, nas quais imbricam objetividade e subjetividade, senso comum e ciência, teoria e prática, cultura e natureza, anulando dicotomias e procurando novos conhecimentos mediante novas práticas.

Enquanto Cunha dialoga com Santos no que concerne à inovação como um olhar diferenciado sobre a construção do conhecimento, Masetto (20032004: 197), por sua vez, propõe um conceito norteador para o tema aplicado ao ES, ao colocar que a inovação é "entendida como o conjunto de alterações que afetam pontos-chave e eixos constitutivos da organização do ensino universitário provocadas por mudanças na sociedade ou por reflexões sobre concepções intrínsecas à missão da Educação Superior." Sobre os pontos-chave e eixos constitutivos, sempre articulados às exigências do mundo atual, Masetto inclui: o projeto pedagógico de curso; objetivos educacionais que abordem ética, política e profissionalismo; reorganização e flexibilização curricular; reconceptualização da disciplina; superação da fragmentação do conhecimento pela integração; utilização de métodos que favoreçam a participação proativa discente; exploração das novas tecnologias; avaliação pelo processo; o professor como mediador pedagógico; formação continuada docente para refletir sobre sua prática e partilha de experiências; oferta de infraestrutura compatível com os objetivos do projeto. Apesar se serem elementos que se afetam mutuamente, tentaremos prosseguir com o foco na estrutura curricular. Quais seriam, então, as propostas de renovação, para não repetir práticas antigas ou incorrer no "velho retocado de novo"? Veiga-Neto (2008: 145) afirma que:

(...) pode-se entender boa parte das novas propostas curriculares como tentativas de desdisciplinarizar os currículos, de modo a mantê-los imunes às crises ${ }^{3}$ que acometem as disciplinas. O raciocínio é simples: se o currículo, por ser disciplinar, contribui no sentido de

3 Crise, para Veiga, vai ao encontro de Santos no sentido de ser um momento histórico que desencadeia, pela contradição, o rompimento com o status quo e provoca novas possibilidades de compreender o mundo. 
trazer a crise para o interior das práticas pedagógicas, então, com a eliminação (ou abrandamento) das disciplinas, mantém-se o currículo mas afasta-se (ou abranda-se) a própria crise.

A simples retirada das disciplinas, logo, não significa inovação, mas um continuísmo disfarçado, pois os pressupostos de sua existência permanecem os mesmos. Assim, é preciso verificar quais são os aspectos no processo de construção de um PPP que enveredam para a organização curricular inovadora que mantém o status quo ou que concebe o novo. Nesse sentido, Veiga (2003) nomeia essas duas possibilidades em inovação regulatória e inovação emancipatória. A primeira representa um movimento unidirecional, originado nas esferas hierárquicas superiores, cuja base epistemológica sustenta-se na técnica, na burocracia e no conservadorismo científico. Segundo a autora, "a inovação é uma simples rearticulação do sistema, visando à introdução acrítica do velho no novo". A segunda é concebida e construída democrática e coletivamente nas bases, a partir da relação dialógica, integradora de diversos saberes (científicos e populares) e comprometida socialmente (porque emana da sociedade). Veiga (2003: 275) reforça a natureza cooperativa do PPP e a corresponsabilidade de seus atores em fazê-lo acontecer:

(...) o projeto é um meio de engajamento coletivo para integrar ações dispersas, criar sinergias no sentido de buscar soluções alternativas para diferentes momentos do trabalho pedagógico-administrativo, desenvolver o sentimento de pertença, mobilizar os protagonistas para a explicitação de objetivos comuns definindo o norte das ações a serem desencadeadas, fortalecer a construção de uma coerência comum, mas indispensável, para que a ação coletiva produza seus efeitos.

Sendo o PPP do Setor Litoral motivado pela inovação emancipatória, seu projeto prima pela inter e transdisciplinaridade, tendo nos PPC a ausência da estrutura disciplinar clássica (rígida, desintegrada do todo e preocupada 
só com a sua parte) e a presença da estrutura modular (maleável, articulada com outros módulos para dar significado de completude). Masetto (2012: 233) considera que a nova organização curricular “(...) não é construída a partir de disciplinas, mas sim a partir de problemas profissionais contextualizados. Parte-se do concreto, abstrai-se a caminho de uma sistematização teórica e se retorna ao concreto transformando-o". Como esta questão será abordada na próxima seção, passa-se agora a descrever como é composta a equipe de elaboração dos projetos dos cursos.

Organizacionalmente, as câmaras dos cursos foram planejadas para terem docentes do núcleo estruturante e praticamente metade de seus membros de áreas distintas da formação básica ofertada (por exemplo, um professor da área de Física participa da Câmara de Licenciatura em Ciências - por proximidade - e da Câmara de Serviço Social - por distanciamento). O objetivo era ter o contraponto do olhar do especialista para explorar os múltiplos pontos de vista a partir de leigos naquela determinada área, mas detentores de saberes empíricos e científicos acumulados ao longo do magistério e da vida acadêmica. Não é preciso muito esforço para imaginar as reuniões de planejamento pedagógico como espaços de trocas intensas e tensas, mas cuja riqueza do produto é inegável. Apesar de o PPP ter ofertado pouca margem para discussão estrutural, pois seus pilares pertenciam a um "plano maior", poder-se afirmar que a construção dos PPC (vide a diversidade teórico-metodológica de cada graduação) é fruto de trabalho coletivo com o objetivo comum de contribuir para a região circunvizinha. Contudo, apesar de haver clareza em vários pontos para a exequibilidade do projeto, uma das dificuldades que aparenta permanecer na pauta das Câmaras é o processo avaliativo.

A avaliação é um tema espinhoso no campo educacional, pois pode cair, como nas múltiplas leituras em relação ao verbo inovar, em um momento vazio para professor e estudante. O PPP também não esclarece objetivamente (se é que isso poderia ser possível) o quê, como e por quê avaliar a partir dos pressupostos da educação emancipatória. Faz-se esse destaque porque nem todos os docentes do campus tiveram formação pedagógica suficiente para incorporar em sua prática algo com que, possivelmente, não tiveram contato em sua carreira. Pelo contrário: boa parte produziu dentro de sua 
especificidade na graduação e na pós-graduação onde, tradicionalmente, as avaliações são pontuais e resultavam em uma nota. As orientações que o PPP (UFPR, 2008: 32-33) apresenta são: “avaliação processual de múltiplos objetivos, através de indicadores progressivos"; os participantes; e os conceitos (sem descrevê-los qualitativamente), aprendizagem plena (APL), aprendizagem suficiente (AS), aprendizagem parcialmente suficiente (APS) e aprendizagem insuficiente (AI). Assim, uma avaliação inovadora emancipatória requer um investimento maciço em formação continuada e muita partilha de experiência entre os docentes para que uns possam aprender com os resultados dos colegas.

As características elencadas do PPP do Setor Litoral, até o momento, parecem ser de conhecimento interno, vivenciado somente por quem está no cotidiano da instituição. Para a comunidade externa, chamada constantemente a participar das atividades acadêmicas, talvez a flexibilidade curricular, preconizada pelo Parecer CNE/CES n776/97 e ratificada pelas diretrizes do REUNI, seja o diferencial mais explícito, pois há movimentos de ida e vinda mútuos para dentro e para fora dos muros (não somente na extensão, mas também no ensino) e, geralmente, boa parte dos recém-ingressos (principalmente de Matinhos) já conhecem as dinâmicas específicas de cada espaço formativo. Contudo, Catani, Oliveira e Dourado (2001: 175) problematizam a questão e alertam ao relembrar outras intencionalidades veladas da normativa:

Todo esse ideário da flexibilização curricular, assimilado pelos documentos das instâncias executivas responsáveis pela formulação de políticas para a graduação no país, parece decorrer da compreensão de que estão ocorrendo mudanças no mundo do trabalho e, consequentemente, nos perfis profissionais, o que ocasiona a necessidade de ajustes curriculares nos diferentes cursos de formação profissional. Tais dinâmicas certamente "naturalizam" o espaço universitário como campo de formação profissional em detrimento de processos mais amplos, reduzindo, sobretudo, o papel das universidades. 
Na sequência, será apresentada brevemente a organização curricular e como ela se relaciona com o curso de LinCom.

\section{O PROJETO POLÍTICO-PEDAGÓGICO DO SETOR LITORAL E AS ATIVIDADES DE ENSINO NO CURSO}

O PPP do Setor Litoral organiza os componentes curriculares em três eixos pedagógicos distintos em natureza constitutiva, mas articulados pela intencionalidade de flexibilização curricular: os Fundamentos Teórico-Práticos (FTP), que geralmente ocupam três dias da semana; as Interações Culturais e Humanísticas (ICH), que ocorre uma vez por semana; e os Projetos de Aprendizagem (PA), que também acontece em um dia por semana. Os eixos são organizados por fases: Conhecer e Compreender (de um a dois semestres), voltada para o reconhecimento da realidade da região litorânea e introdução ao mundo universitário; Compreender e Propor (de três a quatro semestres), planejada para o aprofundamento teórico-metodológico; e Propor e Agir (de um a dois semestres), que é a preparação para a o exercício profissional.

Além do PPP, a Câmara de LinCom construiu o PPC embasando-se nas Diretrizes Curriculares Nacionais (DCN) de Letras (Parecer CNE/CES n492/2002 e Resolução CNE/CES n 18/2002) e nas DCN de Formação de Professores da Educação Básica (Parecer CNE/CP 09/2001, Parecer CNE/ CP 28/2001, Resolução CNE/CP 02/2002), por ser uma licenciatura em língua (se fosse um bacharelado, haveria mais flexibilidade curricular). Assim, seriam trabalhados os conteúdos de estudos linguísticos, estudos literários, processo de ensino e aprendizagem de línguas e mídia-educação. Este último pensado para a formação de docentes em uma sociedade da informação, tecnologia e altamente midiatizada. A carga horária total excede a mínima prevista nas DCN por ser integralizada em quatro anos (chegando praticamente a 3200 horas). Na sequência, distingue-se a natureza de cada eixo pedagógico e seu modus operandi.

O eixo de FTP concentra as atividades voltadas para a formação específica profissional na qual o estudante deseja graduar-se. Logo, é nesse espaço que os estudantes de LinCom estudam os conteúdos em linguística, litera- 
tura, mídia-educação, prática de ensino, fundamentos da educação e estágio supervisionado (que é feito no turno do curso para beneficiar os estudantes trabalhadores). A carga horária destinada para os FTP corresponde a $60 \%$ do total do curso. A metodologia proposta pelo PPP é a do ensino por projetos, no entanto são poucos os cursos do campus que conseguiram implantá-lo, incluindo a graduação em tela. A quantidade de docentes para trabalhar os conteúdos deste eixo nos quatro anos, conforme dito anteriormente, é de aproximadamente oito, variando para mais ou para menos dependendo da demanda semestral dos outros cursos (lembrando que os docentes participam de outra Câmara, a qual poderá integrá-los em suas atividades). Além disso, como vimos anteriormente, a quantidade de especificidades teórico-práticas a ser tratadas requereria mais do que três dias por semana para conseguir o aprofundamento e criticidade desejável a um professor de língua em formação.

$\mathrm{O}$ espaço de ICH foi concebido em contraponto à formação excessivamente técnica predominante no ensino superior e busca resgatar a ideia de que, antes da formação profissional, os indivíduos lidarão com seus semelhantes ao longo de suas vidas. Inicialmente, em 2006, a sensibilização dos discentes era através de atividades coletivas com profissionais de áreas específicas (palestras, conferências) ou apresentações artísticas (teatro, dança, música). À medida que ingressavam mais turmas e se avançavam as discussões pedagógicas sobre o eixo, foram estabelecidos alguns parâmetros, quais sejam: organização coletiva e dialogada das atividades por afinidade de interesses, independentemente de serem estudantes de cursos diferentes ou em fases distintas; o papel do docente é de mediador da atividade, não necessitando ser um especialista no assunto eleito pelo coletivo, mas ter interesse em construir conhecimento em conjunto e saber intervir pedagogicamente para que os encontros sejam significativos e justificáveis em um ambiente universitário; o papel do discente é de corresponsável pela condução da atividade, devendo assumir a responsabilidade pelos objetivos traçados em conjunto com o mediador. Os critérios de avaliação do processo são definidos pelo grupo, bem como o instrumento. Ao final de cada semestre os grupos são convidados a participar de uma socialização coletiva das atividades realizadas, chamada de Festival das Interações Culturais e Humanísticas (FICH). 
A carga horária de ICH corresponde a $20 \%$ do total do curso e inicia desde o primeiro semestre. Por abranger e fomentar a diversidade de temas, este eixo possibilita que qualquer docente possa nele atuar, independentemente de sua formação, pois nasce de uma construção coletiva. No entanto, a adesão dos professores, em uma observação empírica, é parcial, ora justificada pela incompreensão sobre a proposta ou sua organização, compreensível pela característica de ruptura das relações de poder e do deslocamento do saber individualizado para o coletivizado, ora pela abrangência ilimitada de temáticas, que gera dúvidas quanto à pertinência da atividade no espaço universitário. Os estudantes de LinCom não são instruídos pelos docentes do curso a construir uma atividade afim, o que permite o trânsito por vários saberes, como por exemplo: LIBRAS, dança gaúcha, documentário e ficção, estudo autônomo, teatro, canto coral, etc.

Os Projetos de Aprendizagem são oriundos dos interesses subjetivos dos estudantes em realizar algo relacionado com sua história de vida ou que despertou interesse a partir da reflexão crítica sobre a realidade regional na fase de Conhecer e Compreender. No primeiro semestre de curso, os estudantes são organizados em turmas para entender o que é construir um projeto, refletir sobre sua trajetória pessoal e encaminhar, no final do processo, uma pré-proposta ao professor cujo plano de ação docente esteja alinhado com seus temas de interesse ou tenha afinidade pessoal (o PPP permite a mediação de PAs por qualquer docente, tendo em vista que o papel é de mediador, alguém que auxiliará na problematização do projeto). Os PAs podem ser desenvolvidos em duplas com colegas do próprio curso ou de outros, mas, dependendo da Câmara, exige-se um produto individual. Anualmente, o Setor Litoral realiza uma Mostra de Projetos com objetivo de divulgar e aproximar a comunidade do que se desenvolve na região. A carga horária de PAs também é de $20 \%$ do total do curso. O curso de LinCom faz dois movimentos para acompanhar os PA de seus licenciandos: realiza um seminário interno semestral e solicita que, no último período, cada discente apresente suas reflexões sobre suas ações no projeto e sua formação para o magistério. No curso, pelo acompanhamento permanente, detectou-se a predileção dos discentes por fazer projetos de temáticas relacionadas ao curso, como: leitura, literatura, fonologia, mídia-educação. 
Pelo exposto, as Câmaras possuem autonomia limitada na definição das atividades dos estudantes, restringindo-se à organização dos FTP. Com isso, os estudantes têm a possibilidade de definir $40 \%$ dos componentes curriculares de acordo com seus interesses pessoais ou outro critério, como subsidiar seus PAs. Em adendo, é perceptível que cada eixo curricular possui objetivos distintos e, necessariamente, exigem formas metodológicas e avaliativas diferenciadas. Nesse contexto, professores e estudantes assumem o árduo desafio de encontrarem um meio termo para que as inovações não repilam ambas as partes pelo estranhamento ou estacionem na zona de conforto da historicamente familiarizada pedagogia tradicional. Em específico, a Câmara de LinCom, por ser este um dos cursos mais recentes, ainda precisa lidar com muitas atividades administrativas e tem dificuldades para discutir os aspectos pedagógicos com a frequência necessária.

\section{SÓ FALTA O VENTILADOR?}

As inovações curriculares no ensino superior são bem-vindas e benquistas. Por exemplo, os eixos curriculares de ICH e PA, mais latentes como espaços inovadores, oxigenam o desejo pela construção de uma universidade solidária, participativa e aberta à comunidade. Porém, como dito anteriormente, o excesso de interesses/interessados exógenos à comunidade universitária influencia diretamente o fazer docente. $\mathrm{O}$ recesso, por outro lado, também tem parcela significativa na qualidade do trabalho (vide a quantidade de professores por curso), o que gera sobrecarga (didática e administrativa) de atividades e diminui o tempo para os intercâmbios pedagógicos e a produção reflexiva de material (artigos, ensaios) para partilhar com outros atores os sucessos, as fragilidades e incertezas. A formação continuada, ofertada majoritariamente nos primeiros quatro anos de implantação do projeto, rareou e questões como avaliação permanecem carentes de aprofundamento de discussões.

A licenciatura em LinCom é uma proposta nova, que ainda precisa afirmar-se epistemológica e politicamente frente aos consagrados cursos de Letras. A evasão discente notada nas duas primeiras turmas é reflexo, sus- 
peita-se, da polissemia causada pelo nome do curso (comunicação remete à comunicação social), da insegurança em ter o diploma aceito em seleções públicas e também da organização curricular que rompe com as práticas na EB e causa estranhamento. Em contrapartida, os graduandos que se identificaram com o PPP demonstram uma desenvoltura promissora para a qualidade das discussões do curso.

À guisa de encerrar a discussão proposta por este artigo, fazem-se algumas considerações consideradas relevantes. A primeira diz respeito à pesquisa científica sobre inovações pedagógicas no Brasil que já produziu alguns materiais, um dos quais refere-se ao PPP do Setor Litoral (MASETTO, 2011: 12) como uma das propostas de ensino superior inovador. A segunda é destacar que as análises apresentadas são um ponto de vista, abrindo espaço para que outros colegas inseridos endogenamente no mesmo ambiente de trabalho e estudo contribuam para o enriquecimento da totalidade da percepção do objeto. A terceira é referente ao papel do autor deste artigo como corresponsável por erros e acertos institucionais, tendo em vista que todos, sem exceção, são chamados a participar do processo decisório do campus nas reuniões do conselho setorial. Portanto, se o tom do texto beirou à crítica incisiva sobre alguma instância, afirma-se que a autocrítica estaria no mesmo patamar. Como professor, temos o dever de saber a quais objetivos e interesses nossa força de trabalho está servindo e nos posicionarmos criticamente sobre isso.

\section{REFERÊNCIAS BIBLIOGRÁFICAS}

BRASIL. Conselho Nacional de Educação/ Câmara de Educação Superior. Orientação para as diretrizes curriculares dos cursos de graduação. Parecer $\mathrm{n}^{\circ} 776$ de 3 de dezembro de 1997.

BRASIL. Conselho Nacional de Educação / Câmara de Educação Superior. Diretrizes Curriculares Nacionais dos cursos de Filosofia, História,

4 O detalhe é que o autor se baseia, para este trabalho, no PPP, datado do ano 2008, e deixou de inserir alguns avanços. 
Geografia, Serviço Social, Comunicação Social, Ciências Sociais, Letras, Biblioteconomia, Arquivologia e Museologia. Parecer n²492 de 3 de abril de 2001.

BRASIL. Conselho Nacional de Educação / Conselho Pleno. Diretrizes Curriculares Nacionais para a Formação de Professores da Educação Básica, em nível superior, curso de licenciatura, graduação plena. Parecer n09/2001 de 8 de maio de 2001.

BRASIL. Conselho Nacional de Educação/ Conselho Pleno. Institui a duração e carga horária dos cursos de licenciatura, de graduação plena, de formação de professores da Educação Básica em nível superior. Resolução n02/2002 de 19 de fevereiro de 2002.

BRASIL. Conselho Nacional de Educação/ Conselho Pleno. Reorganização da carga horária mínima dos cursos de Formação de Professores, em nível superior, para a Educação Básica e Educação Profissional no nível da Educação Básica. Parecer n09/2007 de 5 de dezembro de 2007.

BRASIL. Decreto $\mathrm{n}^{\circ} 5.626$, de 22 de dezembro de 2005. Regulamenta a Lei $n^{\circ} 10.436$, de 24 de abril de 2002, que dispõe sobre a Língua Brasileira de Sinais - Libras, e o art. 18 da Lei $n^{\circ} 10.098$, de 19 de dezembro de 2000. Diário Oficial [da] República Federativa do Brasil. Brasília, DF, 23 de dez. de 2005.

BRASIL. Lei 9.394/96, de 20 de dezembro de 1996. Estabelece as diretrizes e Bases da Educação Nacional. Diário Oficial [da] República Federativa do Brasil. Brasília, DF, 23 de dez. de 1996.

BRASIL. Lei 10.639/2003, de 9 de janeiro de 2003. Altera a lei $n^{\circ} 9.394$, de 20 de dezembro de 1996, que estabelece as diretrizes e bases da educação nacional, para inclui no currículo oficial da Rede de Ensino a obrigatoriedade temática "História e Cultura Afro-Brasileira", e dá outras providências. Diário Oficial [da] República Federativa do Brasil. Brasília, DF, 10 de jan. de 2003. 
BRASIL. Lei 11.645/2008, de 10 de março de 2008. Altera a lei $n^{\circ} 9.394$, de 20 de dezembro de 1996, modificada pela Lei 10.639, de 9 de janeiro de 2003, que estabelece as diretrizes e bases da educação nacional, para inclui no currículo oficial da rede de ensino a obrigatoriedade temática "História e Cultura Afro-Brasileira e Indígena”, e dá outras providências. Diário Oficial [da] República Federativa do Brasil. Brasília, DF, 11 de mar. de 2008.

BRASIL. Plano de Desenvolvimento da Educação/ Reestruturação e Expansão das Universidades Federais. Diretrizes gerais. Brasília: DF, ago. 2007.

BRASIL. Secretaria de Ensino Superior. Coordenação-Geral de Desenvolvimento das Instituições de Ensino Superior. Expansão das universidades federais: o sonho se torna realidade. Brasília: $\mathrm{DF}, \mathrm{s} / \mathrm{d}$.

CATANI, A. M.; OLIVEIRA, J. F. de; DOURADO, L. F. Política educacional, mudanças no mundo do trabalho e reforma curricular dos cursos de graduação no Brasil. In: Educação e Sociedade, ano 12, n.75, ago. 2001.

CUNHA, M. I. Inovações pedagógicas: tempos de silêncios e possibilidades de produção. In: Revista Interface - Comunicação, Saúde e Educação, v.7, n.13, ago., p.149-151. 2003.

FERREIRA, A. B. H. Miniaurélio: o minidicionário da língua portuguesa. 7. ed. Curitiba: Ed. Positivo, 2009.

GATTI. B. A; NUNES, M. M. R. (Org.). Formação de professores para o ensino fundamental: estudo de currículos das licenciaturas em pedagogia, língua portuguesa, matemática e ciências biológicas. São Paulo: FCC/DPE, 2009. p. 57-91/151-154.

MASETTO, M. T. Inovação curricular no ensino superior. In: Revista e-curriculum, São Paulo, v.7, n.2, ago., 2011. 
MASETTO, M. T. Inovação curricular, tecnologias de informação e comunicação e formação de professores. In: Ensino de Língua: das reformas, das inquietações e dos desafios. SIGNORINI, I.; FIAD, R.S. (Org.). Belo Horizonte: Editora UFMG, 2012. p.230-247

MASETTO, M. T. Inovação na educação superior. In: Revista Interface - Comunicação, Saúde e Educação, v.8, n.14, set.-fev, 2003-2004.

SANTOS, B. S. A universidade no século XXI: para uma reforma democrática e emancipatória da universidade. 2. ed. São Paulo: Cortez, 2005.

SANTOS, B.S. Um discurso sobre as ciências. 7. ed. São Paulo: Cortez, 2010.

SAVIANI, D. Formação de professores: aspectos históricos e teóricos do problema no contexto brasileiro. In: Revista Brasileira de Educação, v.14, n.40, jan./abr., p. 143-155. 2009.

UNIVERSIDADE FEDERAL DO PARANÁ. Setor Litoral. Projeto Político-Pedagógico. Matinhos: Setor Litoral, 2008.

VEIGA, I. P. A. Inovações e projeto político-pedagógico: uma relação regulatória ou emancipatória?. In: Cad. Cedes, Campinas, v.23, n.61, p.267281, dez. 2003.

VEIGA-NETO, A. Crise da modernidade e inovações curriculares: da disciplina para o controle. In: Sísifo- revista de ciências da educação, $\mathrm{n}^{\circ} 7$, set./ dez. 2008, p.141-150. 
